\title{
AUTO-ORGANIZAÇAO EM NEONATOS PRE-TERIUIO: COMPORTAMENTOS INTERATIVOS E NÃO INTERATIVOS
}

\author{
SELF-ORGANISATION IN PRE-TERM NEONATES: \\ INTERACTIVE AND NONINTERACTIVE EXPRESSIVE \\ BEHAVIOURS
}

Pessia Grywac Meyerhof ${ }^{1}$

MEYERHOF, R. G. Auto-organização em neonatos pré-termo: comportamentos interativos e não interativos. Rev. Bras. Cresc. Desenv Hum., São Paulo, 9(1), 1999.

Resumo: Neste artigo descreve-se, através de fotografias, os comportamentos expressivos e comunicativos que cada neonato pré-termo pode apresentar além de sugerir modos de atuação do adulto como um facilitador da auto organização do bebê.

Palavras-chave: pré-termo; comportamentos comunicativos.

"Nada é permanente, com exceção da mudança."

Heráclito

Um bebê pré-termo é um organismo único, bem equipado, funcionando adequadamente dentro do seu estágio de desenvolvimento (ALS, 1986); mas, como entendê-lo, visando sua melhor qualidade de vida, presente e futura?

Introduzindo um conjunto sistemático de modificações no ambiente de uma sala de prétermo em Unidade Neonatal no referente às manipulações no neonato pré-termo e à orientação aos pais durante a internação do bebê, MEYERHOF (1996) verificou que estas diminuiram o tempo de internação, o tempo de permanência na incubadora e o período de uso da sonda. Os neonatos mostraram também um controle maior dos estados comportamentais e da estabilidade autônoma, idade fisiológica e comportamental. As medidas utilizadas também compreenderam um programa de sensibilizarão de uma equipe neonatal e dos pais onde a expressão e comunicação do neonato pré-termo foi bastante observada. Será aqui descrito mais detalhadamente parte deste programa que objetivou desenvolver o respeito ao neonato, para que este pudesse colaborar da melhor forma possível durante as manipulações pelas quais precisasse passar.

Segundo BRAZELTON (1994), um bebê em situação de risco pode aprender tanto a fracassar quanto a ser bem-sucedido ao longo do seu

1 Terapeuta Ocupacional. Doutora em Ciências pelo instituto de Psicologia da Universidade de São Paulo; Treinada na utilização da Escala de Avaliação do Comportamento do Neonato de Brazelton em Boston instrutora Senior dos Cursos de Tratamento Neuroevolutivo - Conceito Bobath. Conselheira Técnica do Lar Escola São Francisco. Membro do setor de Desenvolvimento Humano da Disciplina de Pediatria e Neonatologia da Universidade Federal de Medicina/Escola Paulista de Medicina. Diretora Clínica da Reabilitação Especializada - São Paulo. Presidente da Associaçao Brasileira de Divulgação do Método Bobatch ABRADIMENE. 
processo de amadurecimento dependendo, dentre outros fatores, de intervirmos no momento correto. O pré-termo não submetido a uma carga excessiva de estímulos, aos poucos, passa pelo ciclo de seis estados comportamentais observáveis em todos os recém nascidos.

Desde seu nascimento, o bebê aprende a manipular reações psicofisiológicas internas e a controlar a hiper-estimulação externa. Observa-se que, no início, o pré-termo reage melhor a uma única modalidade de estímulo por vez, seja ela ligada ao lato, à voz, ao rosto ou ao fato de estar no colo. É necessário observar cada uma de suas reações pois ele consegue, através da mudança do ritmo da respiração, da alteração da cor da pele (controle autônomo), do seu comportamento motor e do seus estados comportamentais, mostrar se os estimulas estão adequados ou excessivos.

ALS (1986) descreve, dentro do modelo sincrono-ativo do desenvolvimento, os comportamento de auto-regulação do pré-termo: os comportamentos de aproximação, que indicam se o neonato pré-termo está recebendo quantidade de estimulação e interação adequadas, e os comportamentos de retraimento quando se observa se ele está muito estressado e as estimulações que o cercam são excessivas.

De modo semelhante, com base em nossa experiência clínica, classificamos os comportamentos de aproximação e retraimento, denominando-os, contudo, de bem estar e mal estar, e inserindo-os dentro de contexto em que ocorrem: quando o bebê está sozinho, quando está em interação com um adulto, e quando o neonato está sendo submetido a alguma rotina onde é colocado em situação de. A denominação "bem estar" ou "mal estar" se deve à concepção de que se a saúde é o "bem estar “ do corpo (KANT apud GOUBERT, 1997), a qualidade da vida pode ser pensada como o "bem estar na vida”.

Neste artigo, complementarmente à tese acima referida, pretende-se descrever através de fotografias, os comportamentos expressivos e co- municativos que cada neonato pode apresentar e, em uma seguida, sugerir modos de atuação do adulto como um facilitador da autoorganização ${ }^{2}$ do bebê.

\section{OS COMPORTAMENTOS EXPRESSIVOS E COMUNICATIVOS DO NEONATO PRÉ-TERMO}

Os comportamentos expressivos do neonato pré-termo podem ser agrupados em duas categorias: comportamentos não interativos e comportamentos interativos.

Comportamentos não interativos são aqueles que o bebê se auto-organiza, ou não, sem a ajuda do adulto, e comportamentos interativos são aqueles em que o bebê se organiza, ou não, com a ajuda do adulto (ou de outra pessoa).

Os comportamentos não interativos podem ser de bem estar ou de mal estar, e ainda um comportamento onde o neonato procura ativamente $o$ bem estar.

Os comportamentos interativos podem ser comunicativos de bem estar, comunicativo de mal estar, ou ainda comunicativo situacional de bem estar e de mal estar.

\section{Comportamento interativo de bem estar}

Na figura 1 o bebê em decúbito lateral em estado de alerta e, ao acaso, começa a observar uma de suas mãos que está em seu campo visual. Ele aproxima a mão ao rosto, espalmandoa e fixa seu olhar sobre a mesma, juntando a outra mão à primeira (figura 2) e finalmente, na figura 3 , afasta as mãos da sua face, mantendo-as em seu campo visual, conservando-se organizado globalmente.

Comportamentos não interativos de mal estar são os que o neonato tenta se autoorganizar sem a ajuda do adulto, mas o faz de maneira difícil, nem sempre conseguindo o melhor resultado. Na figura 4, o neonato pré-termo consegue deslocar-se alcançando um apoio na planta dos pés,

2 auto-organização: reposta adaptativa ao meio ambiente (ALS. 1986). 
mesmo assim, sem conseguir alcançar a melhor postura para a autoorganização.

Figura 1 - Comportamento não interativo de bem estar. Neonato pré-termo, em decúbito lateral e estado de alerta, começa a observar uma de suas mãos que está no campo visual (Meyerhof, São Paulo, 1999).

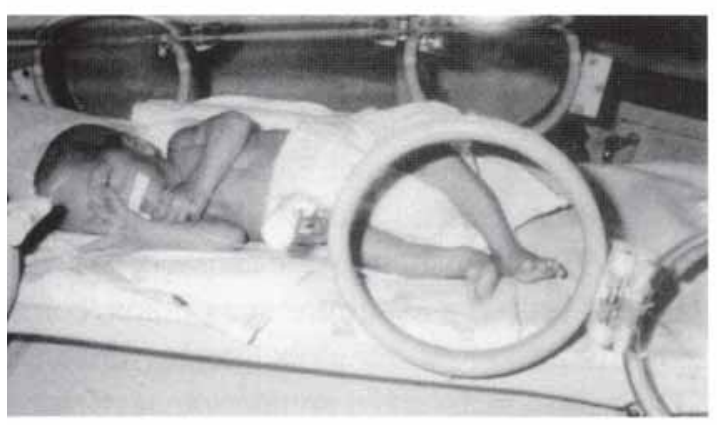

Figura 2 - Neonato pré-termo aproxima a mão ao rosto, espalmando-a e fixa seu olhar sobre a mesma, juntando as mãos (Meyerhof, São Paulo,

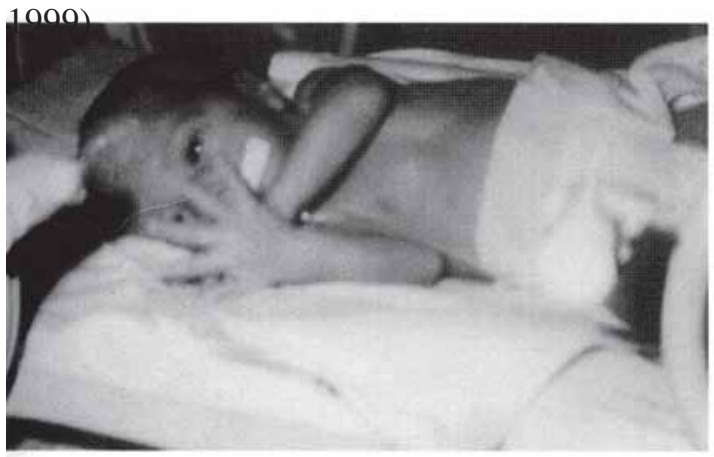

Figura 3 - Neonato pré-termo afasta as mãos da sua face, mantendo-as em seu campo visual, conservando-se organizado globalmente (Meyerhof, S. Paulo, 1999).

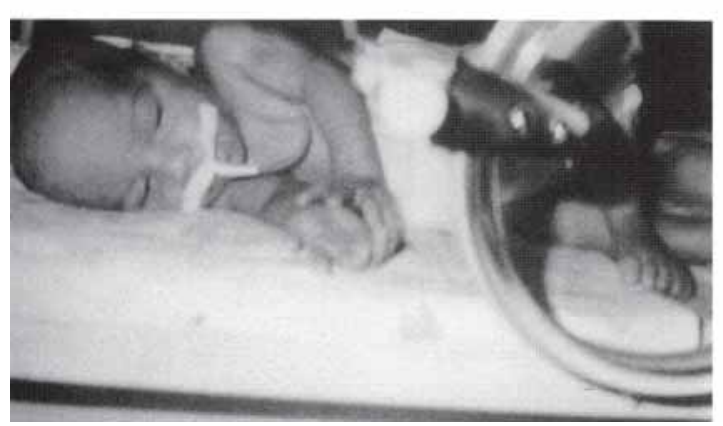

Figura 4 - Neonato pré-termos alcança um apoio na planta dos pés, sem auto-organizar-se (Meyerhof, São Paulo, 1999).

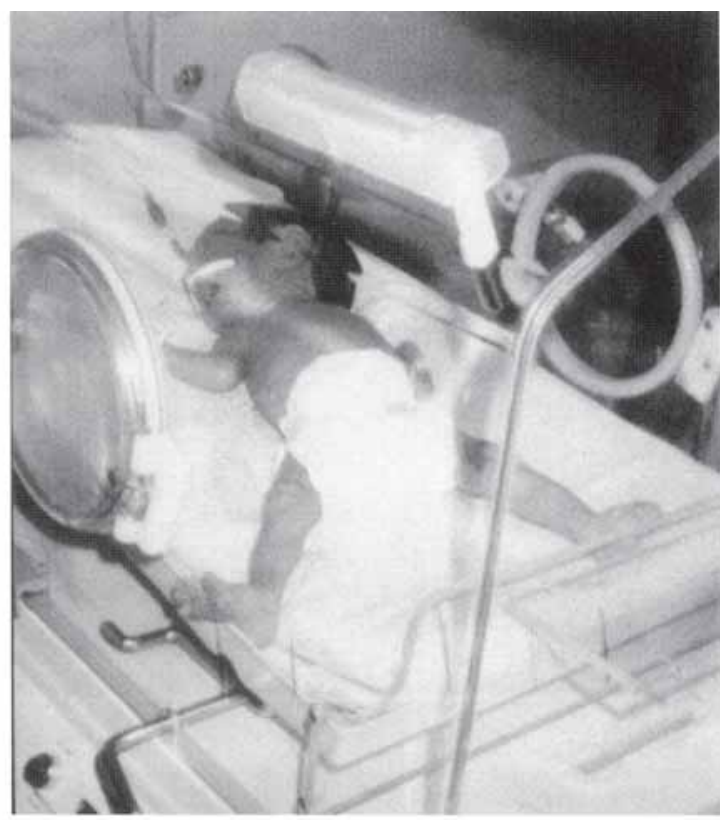

Figura 5 - Neonato procurou um anteparo para a cabeça e para os pés, aumentando sua contenção, organizando-se (Meyerhof, São Paulo, 1999).

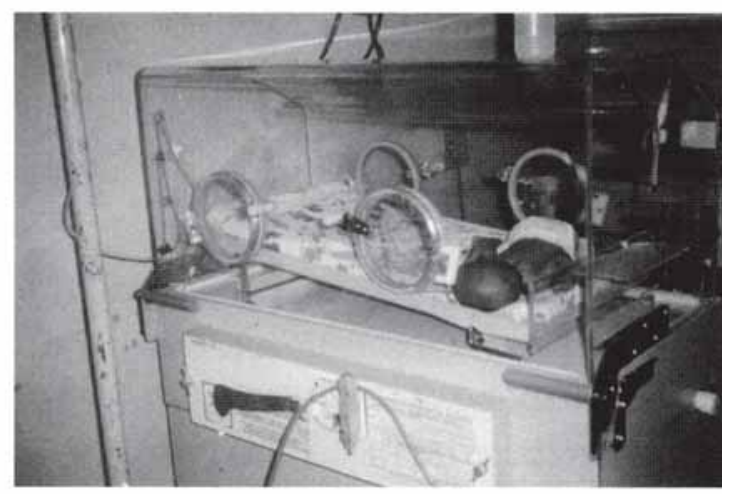

Comportamentos não interativos de procura de bem estar são os comportamentos em que o neonato tenta se organizar sem a ajuda do adulto, mostrando resultado satisfatório. Na figura 5 o bebê procurou um anteparo para a cabeça e para os pés deslocando-se para o fundo da encubadora, aumentando a sua contenção, organizando-se. 
Observa-se na figura 6 que provavelmente, devido ao excesso de estímulo luminoso, o neonato procurou cobrir seu rosto com o cueiro disponível na incubadora.

Figura 6 - Neonato pré-termo cobre seu rosto com cueiro da incubadora, fugindo do excesso de estímulo luminoso (Meyerhof, São Paulo, 1999).

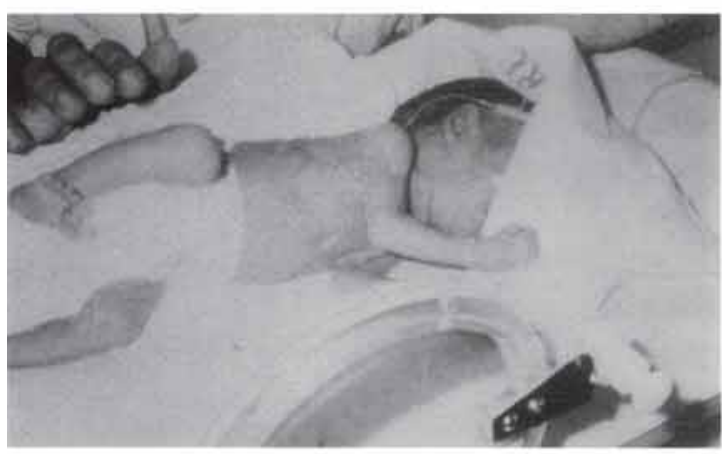

Figura 7 - Neonato pré-termo fixa o olhar na boca do adulto, mantendo-se em estado de alerta (Meyerhof, São Paulo, I 999).

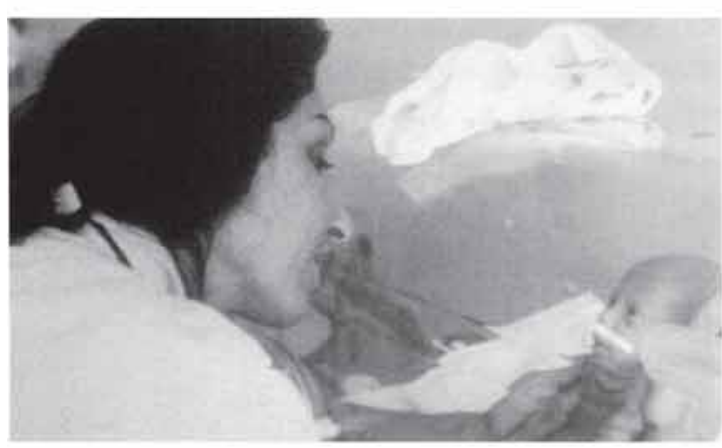

Figura 8 - Neonato leva as mãos ao rosto - sinal que está gostando (Meyerhaf, São Paulo, 1999).

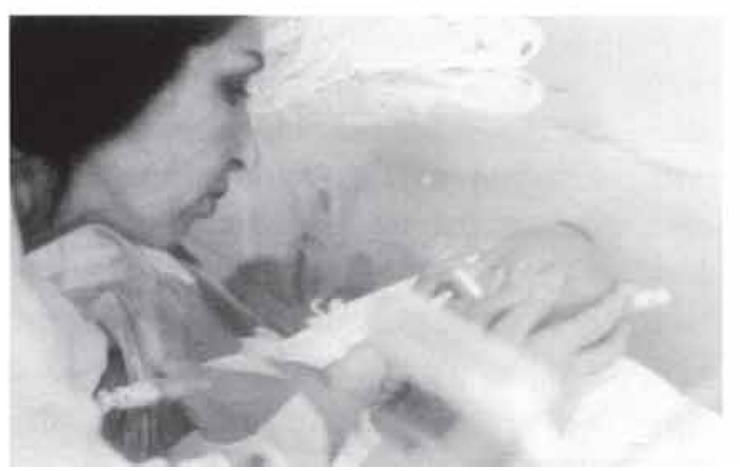

\section{Comportamentos interativos}

Comportamento interativo de bem estar: Na sequência de figuras (figuras 7 a 11), mostrase um episódio de interação bebê-adulto, inicialmente através da fixação do olhar do neonato na boca em movimento do adulto. O bebé se mantém em estado de alerta (figura 7). Ao levar as mão ao rosto, o bebé está “dizendo", em resposta à comunicação do adulto, que ele está bem (segundo ALS, 1986 - figura 8). 0 estado de hiperalerta (olhos grandes como que "amedrontado") prenuncia que ele está ficando cansado (figura 9), demonstrando este cansaço, ao levantar seus braços e espalmar suas mãos, começando a se desorganizar globalmente (figura 10). O neonato conclui sua comunicação perdendo o tono global mas mantendo um sorriso (figura 11).

Figura 9 - Neonato em estado de hiper-alerta, anunciando que está ficando cansado (Meyerhof, São Paulo, 1999).

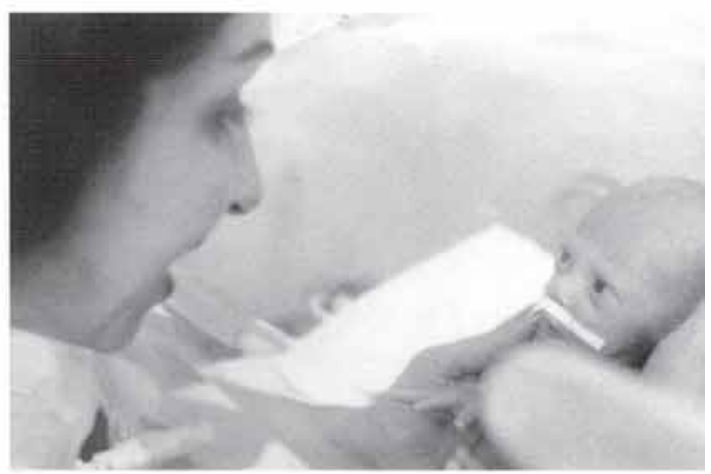

Figura 10 - Neonato levanta seus braço e espalma suas mãos, começando a se desorganizar globalmente (Meyerhof, São Paulo, 1999).

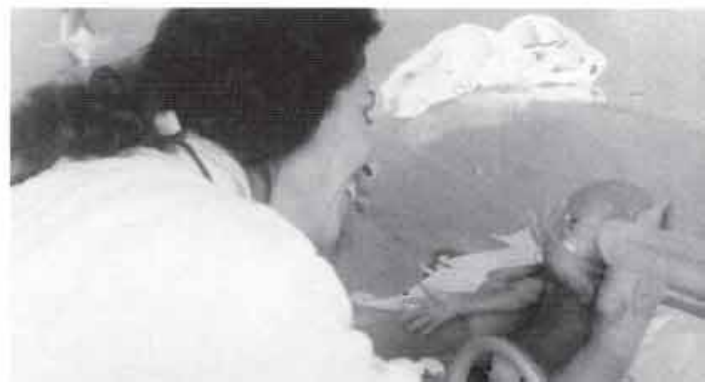


Figura 11 - Neonato conclui a comunicação perdendo o tono global, mas mantendo um sorriso globalmente (Meyerhof, São Paulo, 1999).

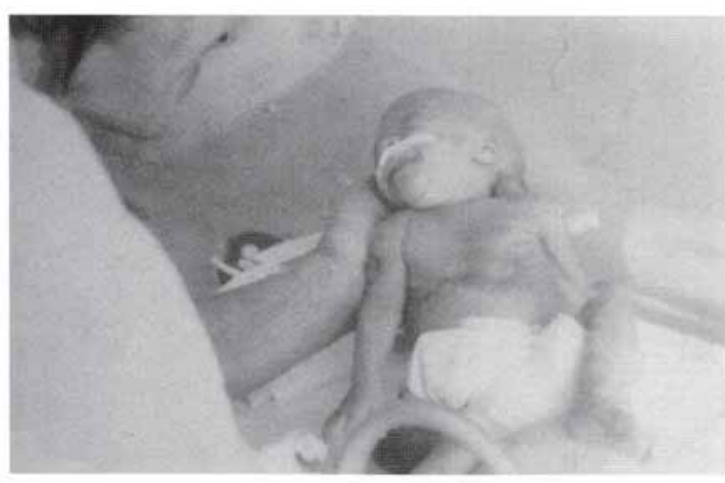

Figura 12 - “Para, para... me dá um tempo! “ Neonato parece precisar se reorganizar antes de terminar a mamadeira (Meyerhof, São Paulo, 1999).

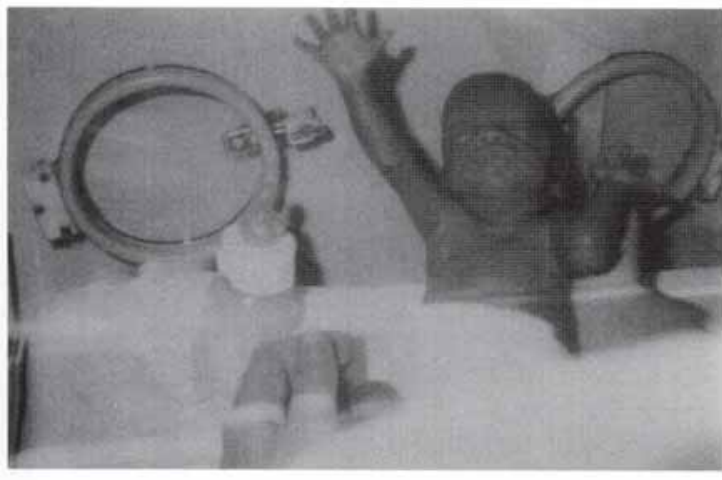

Comportamento interativo de mal-estar é quando o neonato comunica ao adulto que ele necessita que a atividade naquele momento seja interrompida, para que ele possa tentar se auto-organizar.

Ao ser alimentado por mamadeira, dentro da incubadora, na figura 12, observa-se através do levantamento do braço para frente e do espalmar da mão, que o neonato poderia estar comunicando - “pára, pára ... me dá um tempo”. Ele precisa se reorganizar antes de terminar sua mamadeira.

Na figura 13, através do bocejo, o bebé sinaliza que apesar de estar sendo alimentado pela sonda naso-gástrica, ele também precisa de um descanso durante a alinentação.
Figura 13 - Através do bocejo, o bebé sinaliza que provavelmente precisa uma parada durante a alimentação (Meyerhof, São Paulo, 1999).

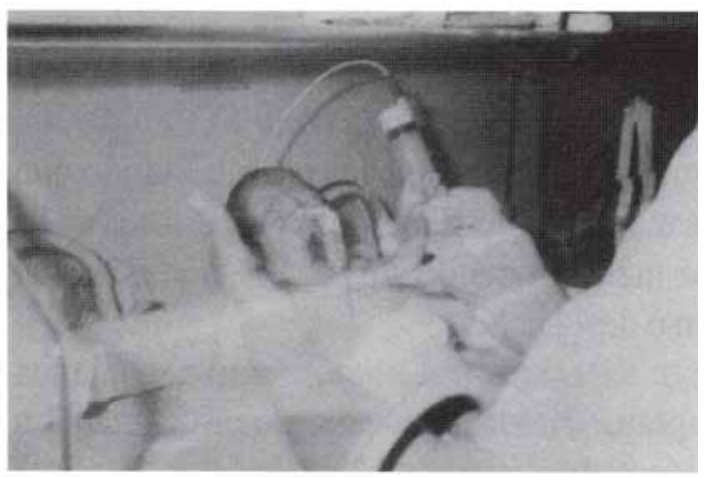

Figura 14 - O neonato parece comunicar seu deseja de encerrar o "bate-papo”levantando seus braços e cerrando seus punhos (Meyerhof, São Paulo, 1999).

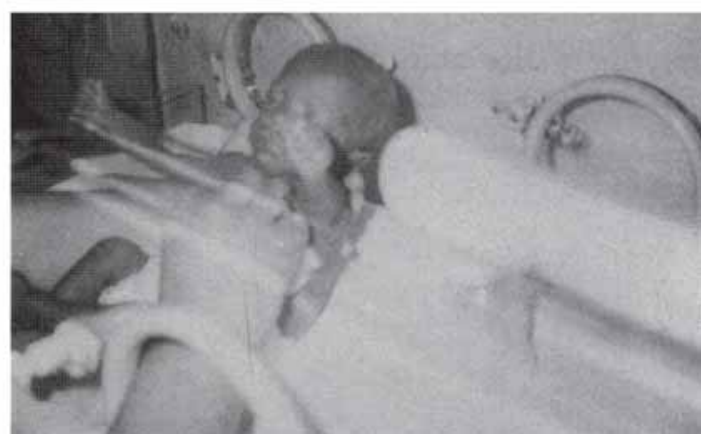

No "bate-papo", o neonato comunica seu desejo de encerrá-lo fechando os olhos, levantando seus braços e cerrando seus punhos como se fosse empurrar o interlocutor (figura 14).

Comportamento interativo situacional é a facilitação da auto-organização do bebé através de arranjos situacionais associados à rotina e/ou à relação bebê-adulto.

A sensibilizarão do adulto deve ser feita na prática, isto é, o adulto observando seu bebé porque cada neonato se expressa singularmente. Contudo, certas manobras mostraram ser eficazes para que o bebé se mantenha organizado por um período mais longo de tempo (BOBATH, 1969; BOBATH \& KONG, 1976; HIJNTFR 1996). 
Exemplificaremos este tópico pelas atividacles de: psicionamento; pesagem; aleitamento.

- Posicionamento. Na seqüência das figuras 15, 16 e 17, o neonato é visto nas posic,ões supino, prona e em decúbito lateral (BOBATH. 1969; BOBATH \& KONG. 1976), contido por rolos de cueiros, facilitando que ele mantenha seus membros superiores na linha média podendo até sugar sua mão, se assim o dosejar.

- Pesagem. Ao ser pesado em balança de prato, o neonato na posição prona mantém seu estado de alerta além de levar a mão à boca (figura 18).

Figura 15 - Neonato em decúbito dorsal. O rolo de cueiro favorcce flexão dos membros inferiores e aproximação dos superiores à linha média dando-lhe maior auto-organização (Meyerhof, São Paulo, 1999 )

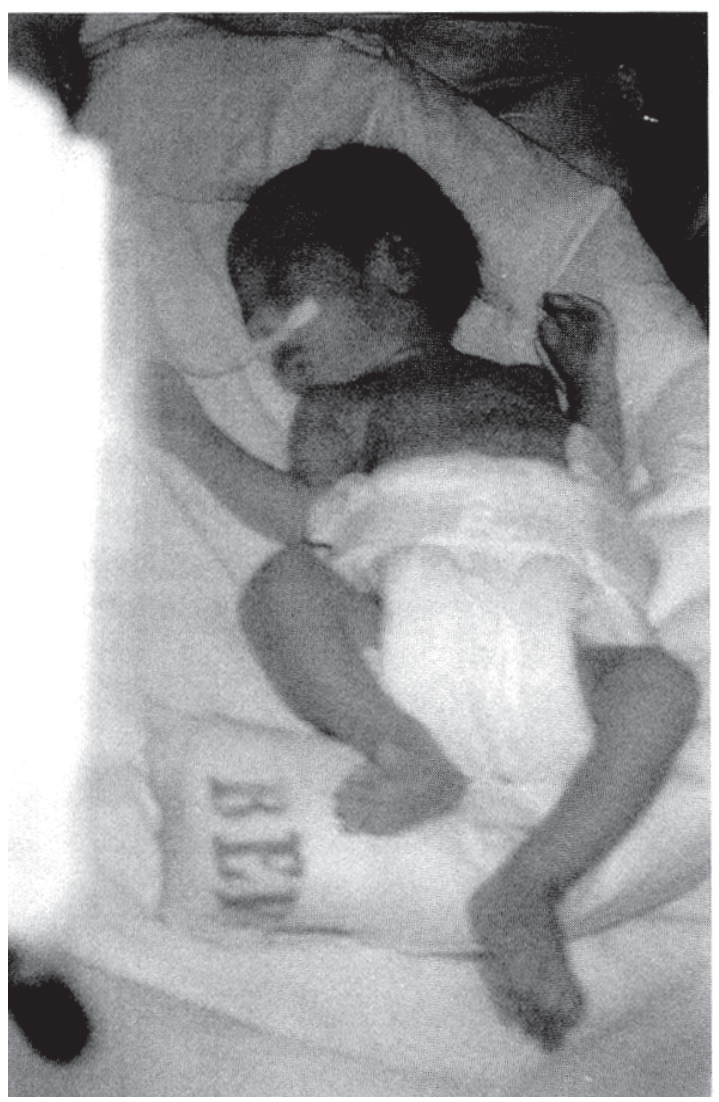

Figura 16 - Neonato em decúbito vcntral com anteparos sob os pés facilitando a auto-organização (Meyerhof, São Paulo, 1999).

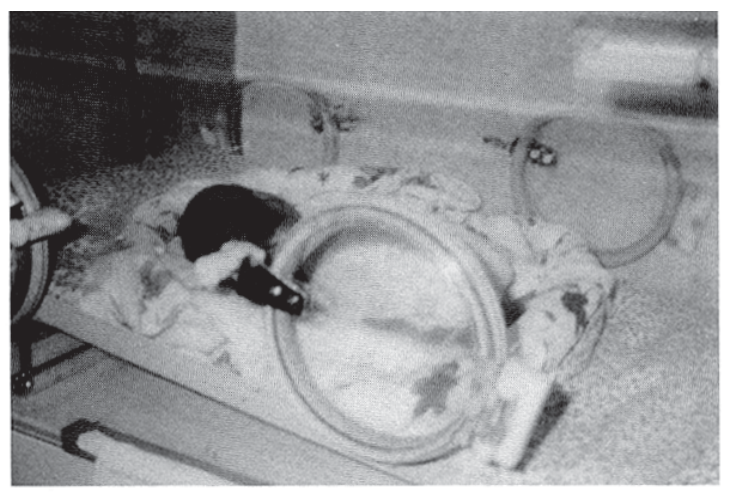

Figura 17 - Neonato em decúbito lateral organizado (Meyerhof, São Paulo, 1999).

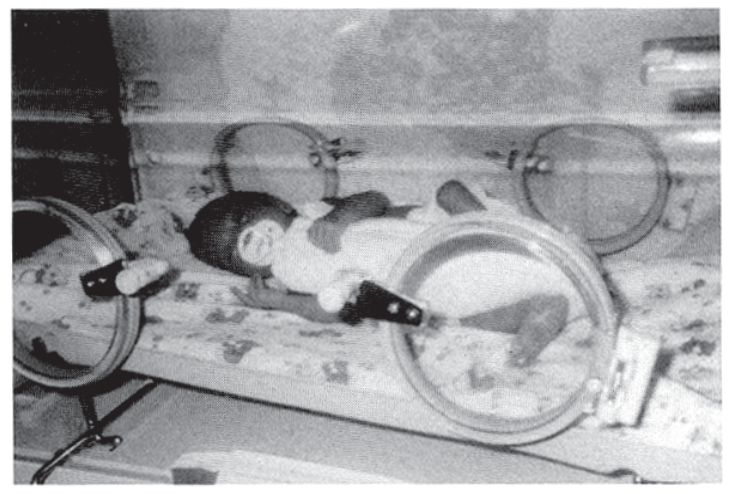

Figura 18 - Neonato sobre a balança de prato em decúbito ventral, postura que facilita levar à mão a boca, organizando-se (Meyerhof, São Paulo, 1999)

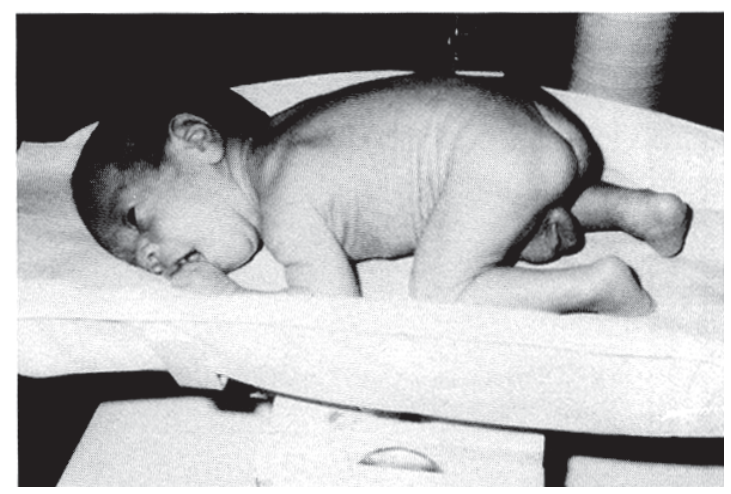


Figura 19 - Durante o aleitamento, ambos os pais participam (Meyerhof, São Paulo, 1999).

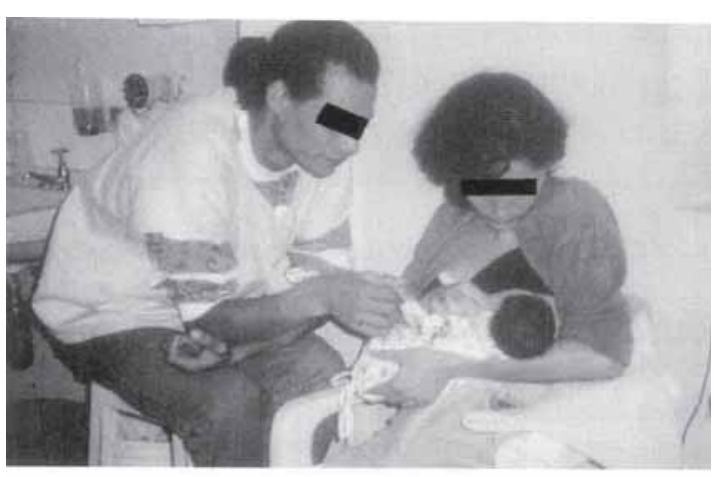

Figura 20 - O pai "brinca" com seu bebê, mantendo uma interação ativa com seu bebê (Meyerhof, São Paulo, 1999).

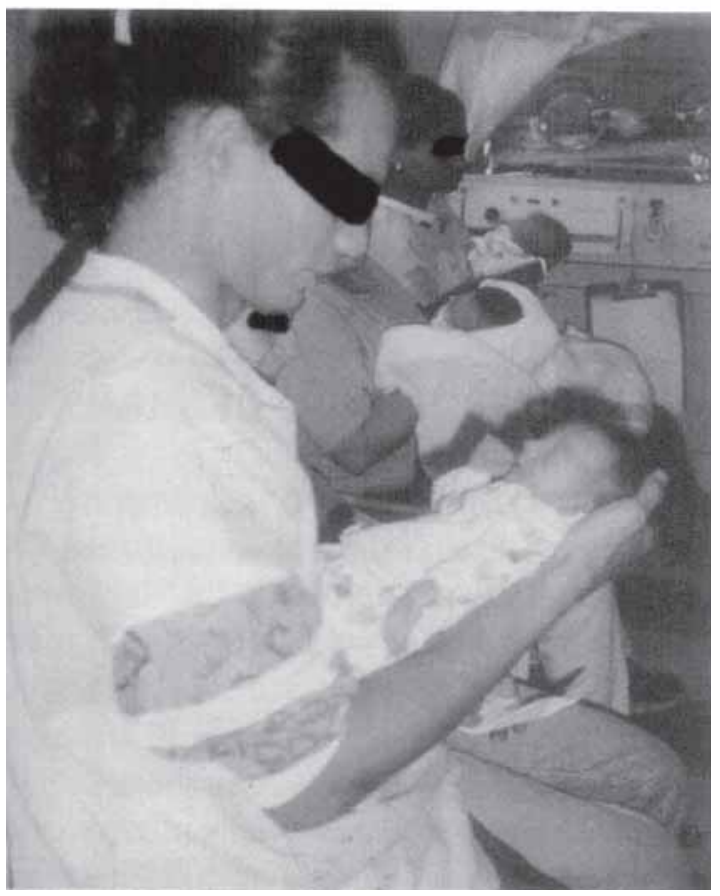

- Aleitamento: As atividade de rotina são ocasiões privilegiadas para propiciar a comunicação entre pais e seus filhos. No aleitamento, por exemplo, a participação de ambos os pais durante e pós aleitamento pode ser muito significativa para o bebê (seqüência de figuras 19 e 20).

\section{CONCLUSÃO}

Qualquer neonato, inclusive o pré-termo, dispõe de um repertório expressivo, singular que, se for "compreendido" pelo adulto, inicia uma comunicação que pode tornar-se uma aprendizagem mútua entre os parceiros.

O bebê, como um sujeito ativo, ao se expressar poderá captar, ou não, a sensibilidade e a interação do adulto em relação a ele.

Esta interação é mútua, e ocorre em um crescente de modo a modificar o comportamento dos participantes, estabelecendo a relação recíproca "adulto-criança".

Este diálogo interativo tem um "ponto ótimo", acima ou abaixo do qual o bebê pode "fechar-se", manifestando-se em sono profundo, devido à hiper ou hipoestimulação.

A confiança do bebê dependerá tanto da sintonia desta interação e da sua capacidade de alcançar e atingir o outro, quanto da sua desistência de fazê-lo, descrendo de suas próprias potencialidades.

Cada bebê possui fragilidades e forças próprias. O adulto pode facilitar a explosão destas forças, assim como destas fragilidades, adequando-as em relação às "permanentes mudanças".

\begin{abstract}
This paper describes pre-term neonate's expressive and communicative behaviours through pictures. It also suggests modes of acting so that the adults become facilitators in relation to the baby's self organisation.
\end{abstract}

Key-words: pre-term neonate; communicative behaviours. 


\section{REFERÊNCIAS BIBLIOGRÁFICAS}

ALS, H. A synactive model of neonatal behavioral organization: framework for the assessment and support of the neurobehavioral development of the premature infant and his parents in the environment of the neonatal intensive care unit. Physical and Occupational Therapy in Pediatrics, 6(314): 3:53,1986.

BOBATH, B. The very early treatment of cerebral palsy. Developmental Medicine and Child Neurology, 9: 373,1969.

BOBATH, K.; KONG, E. Transtornos cerebromotores en el nino. Buenos Aires, Panamericana, 1976. p. 194.
BRAZELTON, T. B. Momentos decisivos do desenvolvimento infantiL Martins Fontes, São Paulo, 1994.

GOUBERT, J. R Cidade e saúde: a organização do tempo e do espaço no Oriente e no Ocidente. Revista Brasileira do Crescimento e DesenvolvimentoHumano, 7(1):1-7, 1997.

HUNTER, J. G. The Neonatal Intensive Care Unit. In: CASE-SMITH ALLEN, S.; PRATT, R N. Occupational Therapy for Children. St. Louis Missouri, Mosby-Year Book Inc., 1996. $3^{\mathrm{a}}$ Ed. p. 583-646.

MEYERHOF, P. G. Qualidade de vida: estudo de uma intervenção em unidade de terapia neonatal de recém-nascidos pré-termo. São Paulo, 1996. [Tese de Doutorado - Instituto de Psicologia da Universidade de São Paulo]. 